\title{
Influence of super \& hyperplasticizers on structuring and properties of cement paste and concrete
}

\author{
Pavel Krasovsky*, and Boris Makhinin \\ Far Eastern State Transport University, 680021, Seryshev Str., 47, Khabarovsk, Russia
}

\begin{abstract}
Research results concerning to influence of super- and hyperplasticizers on the processes of portlandcement paste structure formation and properties of cast concrete are described.
\end{abstract}

\section{Introduction}

In recent years, we can observe significant changes in the field of technology of cement concrete compounds, as the main constructional materials of the 21 st century. Emergence of new compositions implies creation of appropriate technologies and development of new applications of high-quality concretes, as well as studies of their properties. In many countries, concretes, which recently were called new-generation concretes, have become commonplace. Modern high-quality concretes include a wide range of materials for various purposes: high-strength and ultra-high-strength concrete, self-compacting concrete (SCC), highly corrosion-resistant concrete, reactive-powder concrete (RPC), disperse reinforced concrete (DRC or fiber concrete). These types of composites meet high demands on compressive and tensile strength, crack resistance, toughness, corrosion and frost resistance, durability, etc.

The demand for high-quality concretes led, firstly, to advances in methods of concrete mix plasticizing, and secondly, to use the most active mineral supplements (pozzolans) containing nanoparticles of the upper nanometric level $(100 \ldots 300 \mathrm{~nm})$ - silica fumes, disperse ashes, dehydrated kaolins, and so on. The combination of such pozzolans with hyperplasticizers on polycarboxylate, polyacrylate or polyglycol basis allows to obtain water-reduced fluid cement-mineral disperse systems and cast concrete mixes.

The term "Hyperplasticizer" was firmly entered into the use by ready-mixed concretes' and dry mixes' manufacturers, although it has not yet been formally defined in Russia. As a plasticizing agent, in insignificant amount it can radically change rheological properties of mix, hydration processes, physical and technical characteristics of cement paste, mortar and concrete. This explains the increasing interest to develop and apply hyperplasticizers in concrete technology.

\footnotetext{
* Corresponding author: aredigarian.edu@mail.ru
} 
For instance, in 1994-1995 high or superhigh compressive strength of $150 \ldots 200 \mathrm{MPa}$ was achieved, based on fine-grained RPC and DRC technologies using large amounts of microsilica: cement content varied from 550 to $950 \mathrm{~kg}$, microsilica - from 200 to $250 \mathrm{~kg}$ per $1 \mathrm{~m}^{3}$ of concrete; fiber content varied from 2 to $3 \%$ of disperse reinforced concrete's volume.

The use of complex additive providing both fluid mix and high strength characteristics of concrete for high-rise building construction in Moscow set us the task of accumulating experimental data in this field for possible application in our Far Eastern region.

The molecular design based on the chemical modification of carboxyl-containing polymers, allows the introduction of long side oligoalkylene oxide chains into these macromolecules through the formation of corresponding ester or amide groups in development of high-performance water-soluble carboprene hyperplasticizers. This provides virtually unlimited possibilities to control the chemical and physical behavior of polymers and their interaction with cement particles by changing the length of main and side chains, electric charges, density of side chains and free functional groups.

\section{Results}

In general, the chemical composition of polycarboxylate hyperplasticizer of new generation (already the 4th) can be represented by the formula in the Figure 1. The action of such a plasticizer is based on a combination of electrostatic and steric effects, the latter achieved by side hydrophobic polyether chains of polycarboxylate ester. Due to this double effect, plasticizing or water-reducing power of such admixtures is several times higher than that of traditional plasticizers providing only single effect.

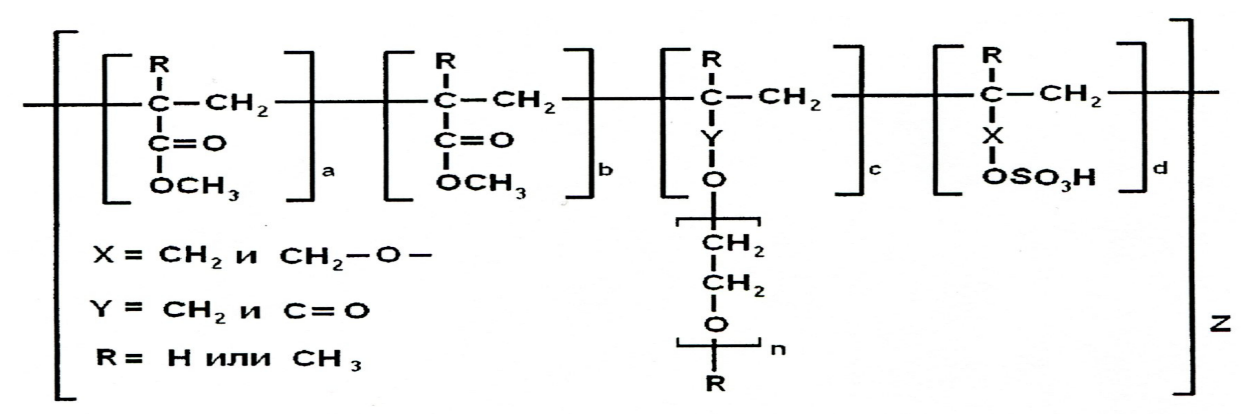

Fig. 1. Structural Formula of the 4th Generation Polycarboxylate Hyperplasticizer

Long-time viability (fluidity, spreadability, plasticity) achieved by means of superplasticizers (SPs) or hyperplasticizers (HPs) is very important technological advantage of cast concrete.

The rheological properties' time evolution patterns shown in the Figure 2, are the same both for plasticized by SPs or HPs and conventional cast concretes. Equal slump-flow $(\mathrm{SF}=22 \ldots 26 \mathrm{~cm})$ mixes with HPs set slowly than control mix without admixtures. Increasing of plasticity to the higher level $(\mathrm{SF}=60 \ldots 64 \mathrm{~cm})$ leads to longer setting and maintaining spreadability during more than 6 hours. However, initially the most fluid mixes with HPs PF3100, PF1190 and PF7100, in 6 hours became sufficiently less spreadable compares to the mix with SP Relamix. 


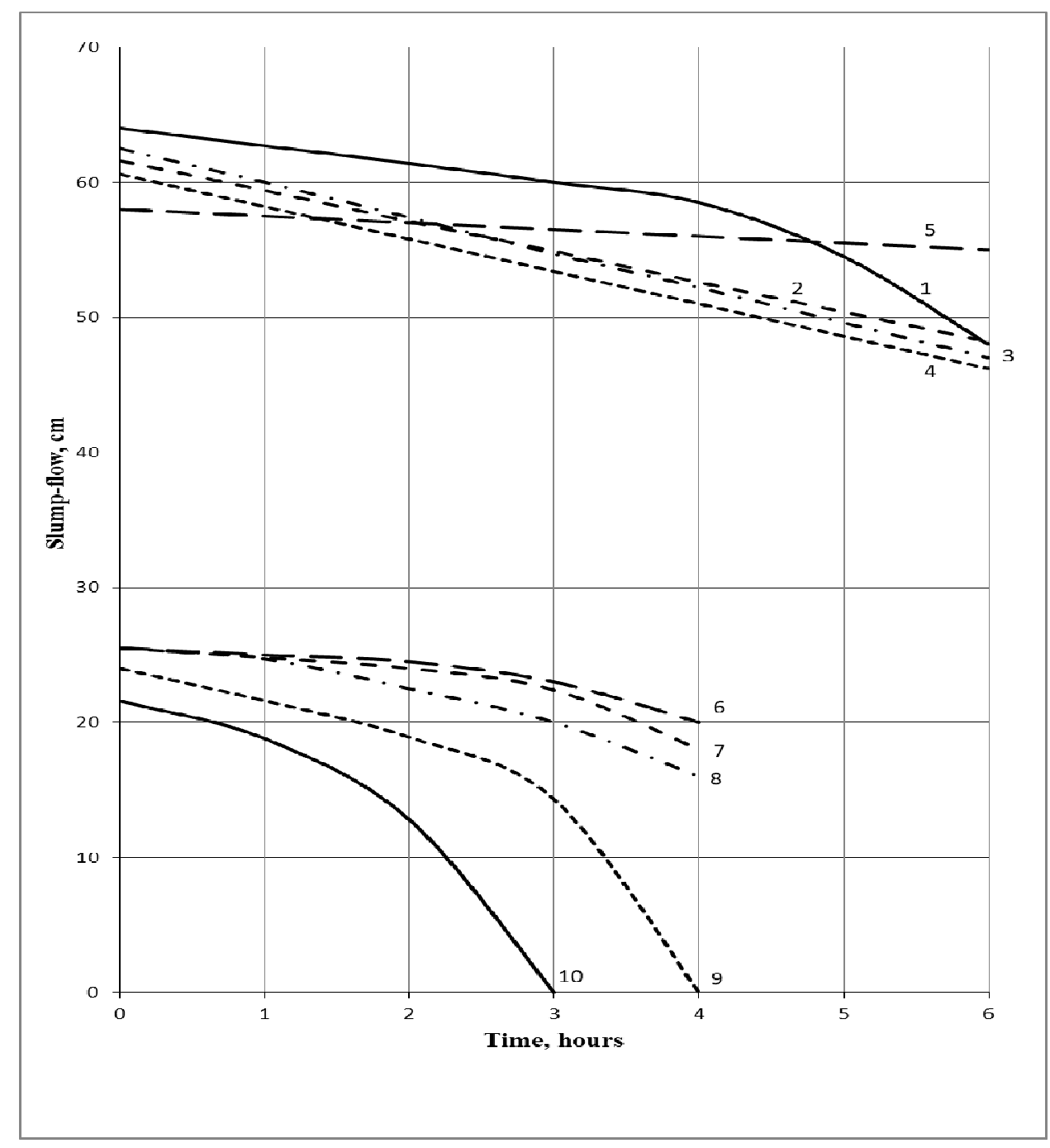

Fig. 2. Viability of Cast Concrete Mixes: $1-$ Control A ( $\mathrm{SF}=64 \mathrm{~cm}), 2-\mathrm{PF} 7100,3-\mathrm{PF} 3100,4-$ PF1190, 5 - Relamix, 6 - FK63, 7 - FK69, 8 - C3, 9 - Kratasol, 10 - Control B (SF = 22 cm)

Observing during a week the processes of contraction occurring in cement pastes with admixtures, we note small increase in contraction volume connected with faster structure formation, than in the control cement paste without additives, as data derived from cement of the Spassk plant illustrate in Table 1.

Table 1. Contraction of Cement Paste, vol. \%

\begin{tabular}{|c|c|c|c|c|c|c|}
\hline Admixture $(0,5$ mass \%) & 1 day & 2 days & 3 days & 4 days & 5 days & 7 days \\
\hline Control & 0,54 & 0,82 & 1,62 & 2,20 & 2,34 & 2,54 \\
PF1190 & 0,88 & 1,28 & 2,30 & 2,48 & 2,60 & 2,94 \\
PF2230 & 0,66 & 0,72 & 1,84 & 1,88 & - & - \\
PF3100 & 2,06 & - & 2,18 & 2,08 & 2,16 & 3,12 \\
\hline
\end{tabular}


This confirms that HPs accelerate hydration processes and increase the degree of cement hydration. Almost all admixtures cause higher contraction of Spassk cement, and the same patterns are inherent for cements of the Teploozersk and Iskitim plants.

The study made it possible to get an idea about the processes of setting and hardening of mineral binders in the presence of plasticizers, leading to emergence of reversible (coagulative) and irreversible (crystallization) spatial structures. The former are formed in suspensions during their sedimentation compaction, as well as in thixotropic systems with colloidal phase; the later - during formation of new crystallization phase. In the cement paste coagulation and crystallization structure formation processes proceed at the same time. Coagulation occurs due to the adhesion of individual cement particles covered with gel-like new-growths, and crystallization occurs due to strong binding of neoproducts as they crystallize from the solution. Mixing cement with water initiates physical-chemical processes, which flow can be conditionally derived into four stages. The first period, characterized by unsteady rate of the cement paste's plastic strength growth, always turns out to be very short. During it, in concentrated suspension the specific surface area of solid phase increases (up to $200 \ldots 300 \mathrm{~m}^{2} / \mathrm{g}$ ) due to formation of new finely dispersed submicrocrystalline phase and a greater number of hydration products particles per volume unit. These conditions determine the higher plastic strength of the cement pastes with SPs C3, FK98 and HPs PF2230, PF3100, as shown on Figure 3.

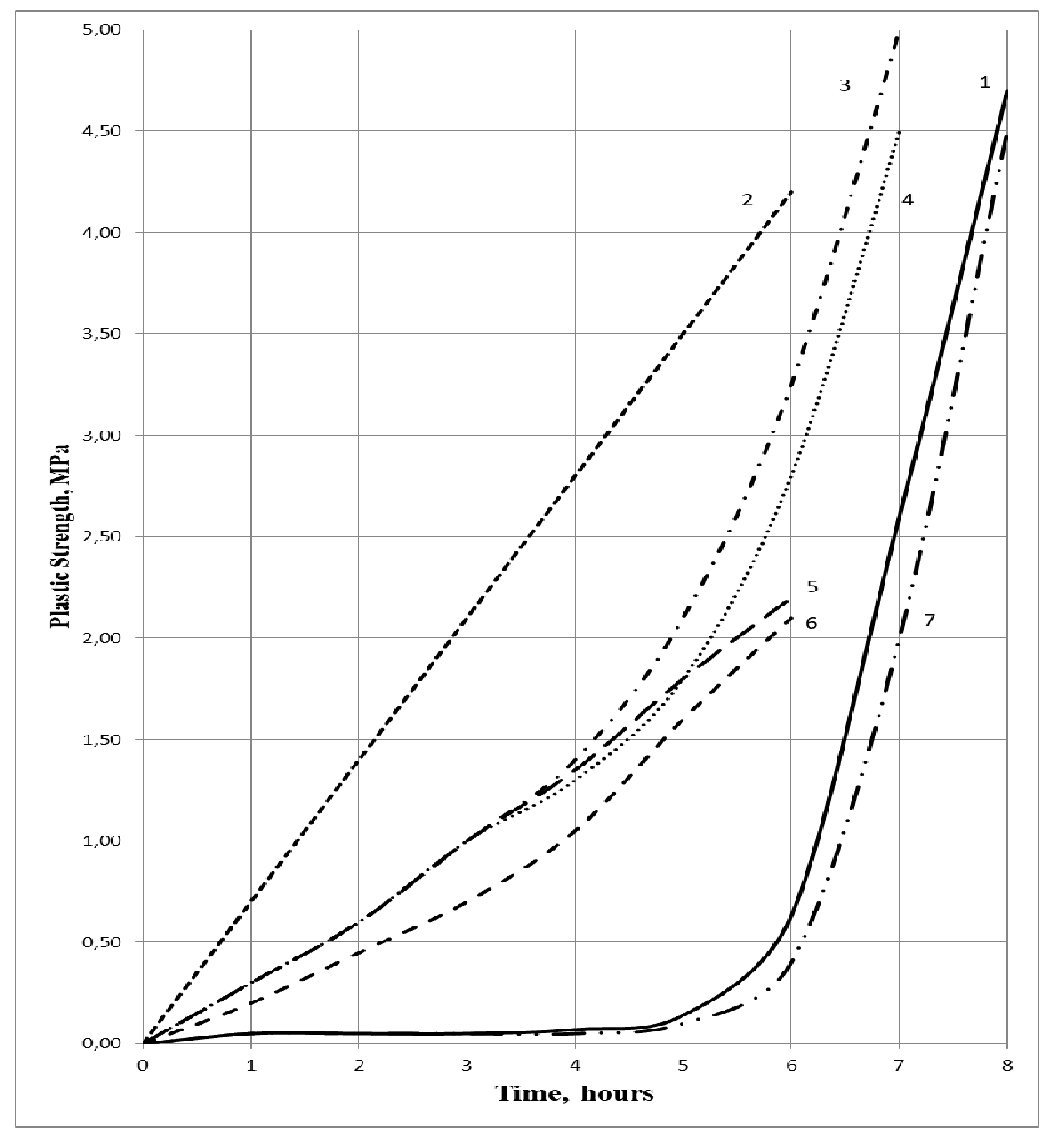

Fig. 3. Plastic Strength of Cement Paste with $0,5 \%$ Admixtures:

1 - Control, 2 - C3, 3 - PF3100, 4 - PF2230, 5 - FK63, 6 - FK69, 7 - FK98 
In the second period of structure formation, intensive allocation of neoproducts occurs in the form of individual crystals slowing down the growth of the solid phase specific surface area. Plastic strength also increases slowly, since the character of solid phase contacts through water shells does not change. The amount of adsorption-bound water increases due to binding of immobilized water to newly formed solid phase surfaces. During this period, the structure retains thixotropic properties. In our experiments, only melamine-formaldehyde SP FK98 slightly interferes setting of cement paste, while naphthalene-formaldehyde SP C3 and polycarboxylate-based HPs PF2230, PF3100, FK63, FK69 dramatically accelerate these processes leading to intensive increase of plastic strength on this stage (and corresponding loss of concrete mix workability).

In the third period, the coagulation structure begins to gradually acquire properties of a hard gel. However, thixotropic properties of hardening cement paste remain until coagulation contacts prevail. This stage is also substantially reduced by means of majority of tested admixtures, reflecting in shortened setting terms. The fourth period is characterized by intensive cement paste plastic strength growth with almost constant speed during the first day. Some admixtures play positive role, slowing down this growth indicated by lower slope of their curves compared to the control paste in the Figure 3 . This is a consequence of slowing down of the crystallization rate, which prevents dangerous structure stresses, leading to appearance of defects in hardened cement paste. By this period the structure of cement stone is basically formed. Further formation of new phases and recrystallization of hydration products can occur only in the pore space. The capillaries' cross section will decrease, and more dense structure with admixtures should look more preferable for better physical-mechanical properties of hardened material. From the point of view of strength, the slower initial growth, the greater final result. Concretes with SPs and HPs confirm this statement, having late compressive strength higher than control samples without admixtures with equal or close w/c-ratios (Table 2).

Table 2. Plasticity and Strength of Cast Concrete

\begin{tabular}{|c|c|c|c|c|c|c|}
\hline \multirow{2}{*}{$\begin{array}{c}\text { Admixture } \\
(0,5 \\
\text { mass } \%)\end{array}$} & \multirow{2}{*}{$\mathrm{W} / \mathrm{C}$} & \multirow{2}{*}{$\mathrm{CS} / \mathrm{SF}, \mathrm{cm}$} & \multicolumn{4}{|c|}{ Compressive Strength, $\mathrm{MPa}$} \\
\hline & & & 3 days & 7 days & 28 days & 360 days \\
\hline \multicolumn{7}{|c|}{ Cement Plant / Crushed Stone Deposit (mineralogy): Spassk / Korf (granodiorite) } \\
\hline Control & 0,50 & $22 / 34$ & 30,0 & 36,2 & 49,0 & 55,0 \\
\hline $\mathrm{C} 3$ & 0,51 & $22 / 37$ & 35,2 & 56,5 & 60,6 & 68,0 \\
\hline PF2230 & 0,48 & $25 / 48$ & 37,2 & 57,0 & 75,0 & 77,0 \\
\hline FK63 & 0,44 & $27 / 65$ & 37,1 & 60,2 & 74,0 & 80,0 \\
\hline \multicolumn{7}{|c|}{ Spassk / Adrian (granite) } \\
\hline Control & 0,51 & $22 / 34$ & 28,5 & 46,3 & 58,1 & 63,7 \\
\hline FK63 & 0,48 & $25 / 62$ & 28,2 & 48,7 & 57,5 & 66,5 \\
\hline \multicolumn{7}{|c|}{ Spassk / Londoko (limestone) } \\
\hline Control & 0,50 & $20 / 32$ & - & - & 38,9 & 54,1 \\
\hline FK63 & 0,44 & $25 / 65$ & 30,1 & 56,2 & 60,3 & 74,0 \\
\hline \multicolumn{7}{|c|}{ Teploozersk / Korf (granodiorite) } \\
\hline Control & 0,50 & $23 / 43$ & 18,2 & 38,8 & 41,5 & 58,2 \\
\hline $\mathrm{C} 3$ & 0,43 & $22 / 45$ & - & 42,3 & 50,8 & - \\
\hline PF1190 & 0,42 & $26 / 65$ & 36,4 & 47,6 & 54,4 & 64,2 \\
\hline PF2230 & 0,40 & $24 / 60$ & 29,0 & 39,0 & 43,3 & 75,4 \\
\hline PF3100 & 0,43 & - & - & 47,1 & 60,8 & 65,1 \\
\hline Relamix & 0,42 & $25 / 60$ & 34,7 & 47,1 & 61,3 & 73,6 \\
\hline \multicolumn{7}{|c|}{ Teploozersk / Kurjan (granite) } \\
\hline Control & 0,50 & $24 / 40$ & 24,4 & 33,4 & 43,2 & 59,5 \\
\hline $\mathrm{C} 3$ & 0,50 & $24 / 47$ & 26,5 & 33,7 & 53,0 & 67,0 \\
\hline PF1190 & 0,41 & $25 / 61$ & - & 40,3 & 54,5 & 61,4 \\
\hline PF2230 & 0,40 & $25 / 52$ & - & 46,1 & 58,5 & 75,8 \\
\hline FK69 & 0,40 & $25 / 69$ & 27,5 & 35,1 & 55,0 & 74,7 \\
\hline
\end{tabular}


The above-mentioned results of our studies of cast concretes obtained using aggregates from various Far Eastern deposits show also that the origin (mineralogy) of coarse aggregate had a weak impact on the compressive strength while w/c-ratio remaining in the range of $0,4-0,5$.

Adhesion of cement matrix to steel reinforcement does not exposed to deterioration under influence of applied SPs and HPs. Frost resistance of these concretes practically increases at one standard grade, apparently due to modification of pore structure.

Speaking about the economic aspect of using new plasticizers, it is necessary to monitor the costs of all concrete's components (cement, aggregates and admixtures), which grow unceasingly. In Russia in 2009, the HPs' prices exceeded 150 rubles per kilogram, in 2018 reached $280 \mathrm{rub} . \mathrm{kg}$, while the average ready-mixed concrete price excluding VAT was $3610 \mathrm{rub} . / \mathrm{m}^{3}$, crushed stone $-1109 \mathrm{rub} . / \mathrm{m}^{3}$, sand $-440 \mathrm{rub} . / \mathrm{m}^{3}$. Taking into account the prices of used admixtures, we receive cost-related data in interrelation with technical characteristics of cast concretes (Table 3).

Table 3. Composition, Properties, and Cost of Cast Concrete

\begin{tabular}{|c|c|c|c|c|c|}
\hline $\begin{array}{c}\text { Admixture } \\
(0,5 \text { mass \%) }\end{array}$ & W/C & $\begin{array}{c}\text { Cement content, } \mathrm{kg} / \mathrm{m}^{3} / \\
\text { Deviation, } \%\end{array}$ & $\begin{array}{c}\text { Compressive strength } \\
\text { in 28 days, MPa } / \\
\text { Deviation, } \%\end{array}$ & $\begin{array}{c}\text { Admixture } \\
\text { cost, rub./kg }\end{array}$ & $\begin{array}{c}\text { Concrete cost }, \\
\text { rub./m } / \\
\text { Deviation, } \%\end{array}$ \\
\hline Control & 0,50 & $645 / 0$ & $49,0 / 0$ & - & $3610 / 0$ \\
\hline C3 & 0,50 & $490 /-24$ & $60,6 /+24$ & 120 & $3315 /-8$ \\
\hline PF1190 & 0,41 & $458 /-29$ & $54,5 /+11$ & 238 & $3486 /-3$ \\
\hline PF2230 & 0,48 & $470 /-27$ & $75,0 /+53$ & 175 & $3383 /-6$ \\
\hline PF3100 & 0,43 & $480 /-26$ & $60,8 /+24$ & 210 & $3520 /-2$ \\
\hline FK63 & 0,44 & $460 /-29$ & $74,0 /+51$ & 278 & $3574 /-1$ \\
\hline
\end{tabular}

\section{Conclusions}

Analyzing the data from the Table 3, we can notice that reduction in cost of concrete due to economy of cement for $24 \ldots 29 \%$ exceeds rise in price at the expense of selected admixtures. Moreover, the plasticized concretes are not only cheaper for $1 \ldots 8 \%$ than ordinary cast concrete, but also they have higher for $11 \ldots 53 \%$ strength. Therefore, until expensive cement continues to rise in price, the use of effective plasticizers is justified.

In conclusion it is necessary to accent that the main contribution to cost and technical efficiency of modern super- and hyperplasticizers is made by an opportunity to receive by their means high-quality concretes with wide range of unique physical-mechanical properties, which significance is hardly likely could be estimated in monetary form.

\section{References}

1. V.N. Vernigorova, D.S. Kostin, D.S. Sadenko, D.V. Uljanov, Building Materials \& Products, 10, 26 (2010)

2. V.V. Babkov, V.N. Mokhov, S.M. Kapitonov, Structure Formation and Destruction of Cement Concretes (Ufa, 2002)

3. P.S. Krasovsky, N.A. Eltsova, Proceedings of the All-Russian Scientific-Practical Conference of Creative Youth with International Participation, 2 (Khabarovsk, 2017) 